\title{
Formulation and in vitro characterization of anticancer drugs encapsulated chitosan/multi-walled carbon nanotube nanocomposites
}

\author{
Rokaya Aly Sobh*, Hanaa El-Sayed Nasr, Wael Sabry Mohamed \\ Department of Polymers and Pigments, National Research Centre, Giza, Egypt.
}

\begin{tabular}{|c|c|}
\hline ARTICLE INFO & ABSTRACT \\
\hline Received on: $29 / 04 / 2018$ & We aimed to combine the nanoscale structure with bio-molecules to open the door for novel biology and nanotechnology \\
\hline Accepted on: 12/09/2018 & applications. Multi-walled carbon nanotube (MWCNT) was combined with the biocompatible polymer chitosan (Cs) \\
\hline Available online: $03 / 08 / 2019$ & $\begin{array}{l}\text { producing the } \mathrm{Cs} / \mathrm{MWCNT} \text { nanocomposite and utilized as a drug carrier for three types of drugs, namely 5-fluorouracil, } \\
\text { curcumin, and water-soluble curcumin derivative. The produced nanocomposite was with a homogenous well-defined }\end{array}$ \\
\hline $\begin{array}{l}\text { Key words: } \\
\text { MWCNTs/chitosan } \\
\text { nanocomposite, controlled } \\
\text { release, anticancer drug. }\end{array}$ & $\begin{array}{l}\text { structure that proved by transmission electronic microscopy, FT-IR, X-ray diffraction, and thermal gravimetric } \\
\text { analysis. The results of cytotoxicity assay measurement showed that the curcumin encapsulated Cs or Cs/MWCNT } \\
\text { nanocomposite presented higher toxicity towards MCF- } 7 \text { cancer cells compared with RPE1 normal cells indicating } \\
\text { to the selective effectiveness of curcumin nanocomposite towards the destruction of the carcinogenic MCF-7 cells. In } \\
\text { vitro release studies showed that Cs/MWCNT nanocomposite possesses better slow controlled release performance } \\
\text { than chitosan indicating that there is a strong association between the drug and CNTs which triggers the release of the } \\
\text { drug for controlled drug release purposes. }\end{array}$ \\
\hline
\end{tabular}

\section{INTRODUCTION}

An ideal drug delivery system should involve targeted delivery and selective controlled release to optimize the efficacy of the proposed drug and minimize the systemic toxicity (Debbage, 2009; Prato and Kostarelos, 2008).

A wide range of nanoscale drug delivery systems has been evaluated in recent years for their excellent properties (Karimi et al., 2010; Moghassemi and Hadjizadeh, 2014; Scheibe et al., 2010). Among them, carbon nanotubes (CNTs) have great attention to be applied in drug carrier system because of their nano diameter, the novel hollow structure, and excellent physicochemical properties, such as the intrinsic stability, structural flexibility, and the ability to prolong the circulation time and hence, the bioavailability of the carried drug molecules (Benito et al., 2009; Yu et al., 2008).

"Corresponding Author

Rokaya Aly Sobh, Department of Polymers and Pigments, National Research Centre, Giza,Egypt.E-mail: rokaya_aly@yahoo.com
In addition, CNTs have high ability to penetrate the living cell without causing death or any damage. But the poor dispersibility of the CNT in aqueous solution limits their application in the pharmacological use. Literature's reports suggested that functionalization of CNTs could overcome their aqueous dispersion and optimize their selective distribution so as to increase the cell penetration and released in a controlled manner. Furthermore, the presence of the CNTs in the nanocomposite is fruitful to increase the cytotoxicity (Nivethaa et al., 2016).

Functionalization can be achieved by including polymers with CNTs through non-covalent interaction to form polymer/ CNTs nanocomposites. Chitosan is one of the common polymers that is used in the modification of CNTs and has been widely applied in medical application (Dang and Leong, 2006; Paul and Sharma, 2000).

Recently, chitosan has attracted great attention in pharmaceutical and biomedical utilization because of its advantageous bioactivity and biological properties such as biodegradability, biocompatibility, and nontoxicity (Sangsanoh and Supaphol, 2006; Wang et al., 2011). 
5-Fluorouracil (5-FU) as an anticancer drug is most extensively employed in chemotherapy treatment. However, like other drugs used for chemotherapy, it affects the growth of normal body cells and often causes many side effects (Yang and Hon, 2009).

On the other hand, curcumin and water soluble curcumin derivative are taken as potential anticancer drugs. Where curcumin is well-known to contain full of antioxidant, anti-inflammatory and anti-carcinogenic properties and inhibits cancer in various tissues but it suffers from difficulties in clinical administration because of low water solubility and degradation in the physiological condition (Kumar et al., 2014).

Thus, it has been suggested that loading these drugs in Multi-walled CNTs (MWCNTs)/chitosan nanocomposite will be effective to optimize their performance to overcome the problematic side effects which were induced by applying the free drug or low-molecular-weight prodrugs.

This current work concerns in the synthesis of a simple biopolymeric composite matrix composed of chitosan and MWCNT. And estimation of its efficiency in the loading of the anticancer drug 5-fluorouracil, curcumin, and curcumin derivative showing the effect of MWCNTs on the efficiency of drug entrapment, stability, cytotoxicity, and the in vitro drug release.

\section{MATERIALS AND METHODS}

Chitosan (M. wt. = 300,000-400,000), deacetylation degree DD 85\%, was purchased from Sigma-Aldrich, MWCNTs were given from Faculty of Advanced Science-Beni Sweif University). Acetic acid, methanol, drugs curcumin and 5-fluorouracil were purchased from Biobasic Canada Inc. Water-soluble curcumin derivative [1,7-bis(5-carboxyphenylazo4-hydroxy-3-methoxyphenyl)-1,6-heptadiene-3,5-dione] was prepared as described previously (Rezq et al., 2011; Sobh et al., 2015). Potassium dihydrogen phosphate $\left(\mathrm{KH}_{2} \mathrm{PO}_{4}\right)$ was given from Gen-Lab (Egypt). Hydrochloric acid $(\mathrm{HCl})$, potassium chloride $(\mathrm{KCl})$, and sodium hydroxide $(\mathrm{NaOH}) 99 \%$ were provided from Modern Lab, Egypt, and all were used as received. All experiments were carried out using double distilled water.

\section{Encapsulation of MWCNTs}

Multi-walled carbon nanotubes CNTs were first purified from metal particles or amorphous carbon by oxidative methods using strong acids $\mathrm{H} 2 \mathrm{SO} 4 / \mathrm{HNO} 3$ as shown in a previous study (Sobh et al., 2018). MWNT was exposed to acid treatment or oxidation process, then the pristine carbon nanotubes CNT are refluxed causing the length of their chain to be reduced and carboxylic groups were generated resulting in increase of their dispersibility and compatibility with common organic solvents. (Jia et al., 2010; Xiao and Wang, 2009; Prakash et al., 2011). Polymeric MWCNTs nanocomposites were prepared by encapsulation of modified MWCNTs by chitosan via solution processing method. Where MWCNT was dispersed in chitosan solution. A stock from chitosan solution in 1\% acetic acid $(5 \mathrm{mg} / \mathrm{ml})$ was prepared. Oxidized MWCNTs $(100 \mathrm{mg})$ were sonicated in chitosan solution $(40 \mathrm{ml})$ for 20 minutes and then stirred at room temperature for 16 hours (Naficy et al., 2009;
Zhang et al., 2009). Cs/MWCNTs nanocomposites were collected in $1 \%(\mathrm{v} / \mathrm{v}) \mathrm{NaOH}$ solution (Laka and Chernyavskaya, 2006) and washed with ultrapure water by ultracentrifugation to remove unbound chitosan, then collected and dried at room temperature to obtain Cs/MWCNTs.

\section{Drug loading}

A stock solution of curcumin and 5-fluorouracil was prepared in ethanol and water, respectively, at a concentration of $1 \mathrm{mg} / \mathrm{ml}$. The drug was loaded by incorporating the required weight of the oxidized MWCNTs or Cs/MWCNTs composite into the required volume of drug solution by sonication for 10 minutes and stirred for 16 hours at room temperature (Zhang et al., 2009). The products were collected and removed free drug by centrifuge to $3,000 \mathrm{rpm}$, at $4^{\circ} \mathrm{C}$ for 10 minutes, and the clear supernatant was carefully collected.

\section{Statement of human and animal rights}

This article does not contain any studies with human or animal subjects performed by any of the authors.

\section{Morphology Analysis}

The structure of the oxidized MWCNT and Cs/MWCNT nanocomposites before and after drug loading were characterized by the transmission electronic microscopy (TEM). The images were attained by JEM-1230-electron microscopy that operated at $60 \mathrm{kV}$. The sample was diluted by water at least 10 times before taking the images and the well dispersed diluted sample was dropped onto a copper grid (200 mesh) and covered with a carbon membrane, then dried at room temperature.

\section{Drug entrapment efficiency (EE)}

Determination of the drug entrapment efficiency involves the determination of the content of drug in polymers that was carried out by an indirect method (Moustafa et al., 2013; Sobh et al., 2015), where the free drug (unloaded drug) was measured. The unloaded free drug was determined in the clear supernatant following precipitating chitosan solution by adding drops of $\mathrm{NaOH}$ solution and separation of nanoparticles by ultracentrifugation at 5,000 r.p.m. for 30 minutes. The free drug concentration in the solution was determined by measuring the absorbance at $\lambda_{\max } 380,300$, and $265 \mathrm{~nm}$ for curcumin, curcumin derivative, and 5-fluorouracil, respectively, on a Shimadzu Ultraviolet-visible spectrophotometer with the double beam. A standard calibration curve for the free drug with methanol solutions was experimentally obtained.

The drug EE can be calculated using the following equation (Valot et al., 2009):

$$
\text { Entrapment Efficiency }(\%)=\frac{\begin{array}{c}
\text { The weight of the drug entrapped } \\
\text { in the polymeric nanoparticles }
\end{array}}{\text { The weight of the drug initially used }} \times 100
$$

\section{FTIR spectroscopy}

The FTIR spectra of the MWCNT, MWCNT/chitosan nanocomposites free from drugs, loaded with drugs and free drugs were recorded in the range of 4,000-400 $\mathrm{cm}^{-1}$ using $\mathrm{KBr}$ pellets on an FTIR spectrophotometer (Thermo Nicolet, NEXUS, TM). 


\section{X-ray diffraction (XRD)}

X-ray diffraction (XRD) patterns of drugs and MWCNT/chitosan nanocomposites either free from drugs or loaded with drugs were performed using a diffractometer equipped with a rotating target X-ray tube and a wide-angle goniometer. The X-ray tube was operated at a potential of 45 $\mathrm{kV}$ and a current of $40 \mathrm{~mA}$. The X-ray source was Ka radiation from a copper target with graphite monochromate. The scan was performed with a range of 2 hours at a speed of $4^{\circ}$ per minute from $10^{\circ}$ to $80^{\circ}$.

\section{Thermal gravimetric analysis (TGA)}

Free drugs, Cs/MWCNT composite, and drug-loaded Cs/MWCNT composite were analyzed by TGA. A sample of $5 \mathrm{mg}$ was placed on a thin platinum pan and the measurement was carried out at a heat flow rate of $10^{\circ} \mathrm{C} /$ minute under nitrogen at a temperature range between $30^{\circ} \mathrm{C}$ and $600^{\circ} \mathrm{C}[14,15]$.

\section{Cytotoxicity assay}

This cytotoxic activity test (In vitro bioassay on human tumor cell lines) was conducted and determined by the Bioassay-Cell Culture Laboratory, National Research Centre. Cell viability was assessed by the mitochondrial-dependent reduction of MTT assay (Mosmann, 1983). Procedure: Cells were suspended in DMEM F12 medium, 1\% antibioticantimycotic mixture and $1 \% \mathrm{~L}$-glutamine at $37^{\circ} \mathrm{C}$ under $5 \%$ $\mathrm{CO}_{2}$. Cells were batch cultured for 10 days, then seeded at a concentration of $10 \times 10^{3}$ cells/well in 96-well microtiter plates for 24 hours under $5 \% \mathrm{CO}_{2}$ using a water-jacketed carbon dioxide incubator. Media was aspirated, fresh medium (without serum) was added, and cells were incubated either alone (negative control) or with different concentrations of the sample to give a final concentration of (100-50-25-12.5-6.25$3.125-0.78$ and $1.56 \mu \mathrm{g} / \mathrm{ml})$. After 48 hours of incubation, the medium was aspirated, $40 \mu 1$ MTT salt $(2.5 \mu \mathrm{g} / \mathrm{ml})$ was added to each well and incubated for further 4 hours at $37^{\circ} \mathrm{C}$ under $5 \% \mathrm{CO}_{2}$. A positive control which composed of $100 \mu \mathrm{g} / \mathrm{ml}$ was used as a known cytotoxic natural agent which gives $100 \%$ lethality under the same conditions (Bassyouni et al., 2014; El-Sharkawy and Mahmoud, 2016). After treatment cells were incubated with MTT $(10 \mu 1,5 \mathrm{mg} / \mathrm{ml})$ at $37^{\circ} \mathrm{C}$ for 4 hours and then with DMSO at room temperature for 1 hour. Viable cells were determined by measuring the absorbance at $595 \mathrm{~nm}$ using a microplate multi-well reader (Bio-Rad Laboratories Inc., model 3350, Hercules, California, USA). The percentage of change in viability was calculated according to the formula (Nivethaa et al., 2016):

$$
\text { Cell viability } \%=\frac{\text { A } 595 \text { of treated cells }}{\text { A } 595 \text { of control cells }} \times 100
$$

\section{In vitro release studies}

The in vitro drug release tests of the studied anticancer drugs from $\mathrm{Cs}$ and $\mathrm{Cs} / \mathrm{MWCNTs}$ nanocomposites were performed using a dialysis bag method in a vessel containing dissolution media that can act as simulated intestinal fluid or simulated gastric fluid (Joshi et al., 2009).

Simulated intestinal fluid is a phosphate buffer saline with $\mathrm{pH} 7.4$ was synthesized by adding $0.1 \mathrm{M} \mathrm{NaOH}(195.5 \mathrm{ml})$ to $0.1 \mathrm{M} \mathrm{KH}_{2} \mathrm{PO}_{4}(250 \mathrm{ml})$. While simulated gastric fluid is a buffer solution with $\mathrm{pH} 1.2$ was synthesized by adding $0.2 \mathrm{M} \mathrm{KCl}(147 \mathrm{ml})$ to $0.2 \mathrm{M} \mathrm{HCl}(250 \mathrm{ml})$. Dialysis bags (molecular weight cut-off 12 $\mathrm{kDa}$, Sigma) were immersed in the buffer solution for equilibration for 3 hours before experiments (Moustafa et al., 2013). $0.5 \mathrm{~g}$ of polymeric nanocomposites loaded with drug in $3 \mathrm{ml}$ of dissolution media (buffer saline) was introduced in the dialysis bag and placed into receptor compartment containing $50 \mathrm{ml}$ of the dissolution media BS and kept closed under stirring $(100 \mathrm{rpm})$ to avoid losing the media at constant temperature of $37^{\circ} \mathrm{C} \pm 0.5^{\circ} \mathrm{C}$ (Liu et al., 2013). Three milliliter of sample was withdrawn at definite ranges of time for analysis of drug released and an equal volume of fresh buffer was added to maintain sink conditions. The concentration of drug released was measured by UV-spectrophotometer at the maximum absorption wavelength of each drug $\lambda_{\text {max }} \mathrm{nm}$ using the standard curve for each drug.

\section{RESULTS AND DISCUSSION}

MWCNTs were functionalized by oxidative process in our previous work (Sobh et al., 2018) to create function groups (hydroxyl and carboxyl) on MWNTs, (Jia et al., 2010) which renders MWNTs more compatible with common organic solvents to avoid aggregation and help in better dispersing and stabilization of the CNTs within a polymer matrix (Prakash et al., 2011; Sahoo et al., 2010).

Polymeric MWCNTs nanocomposites were synthesized by encapsulation of MWCNTs by biodegradable and biocompatible natural polymer chitosan to be used as delivery devices for anticancer drugs. The purpose of encapsulation is to reach to optimum delivery of bioactive molecules through controlled sustained prolonged release at the targeted sites. Cs/MWCNT

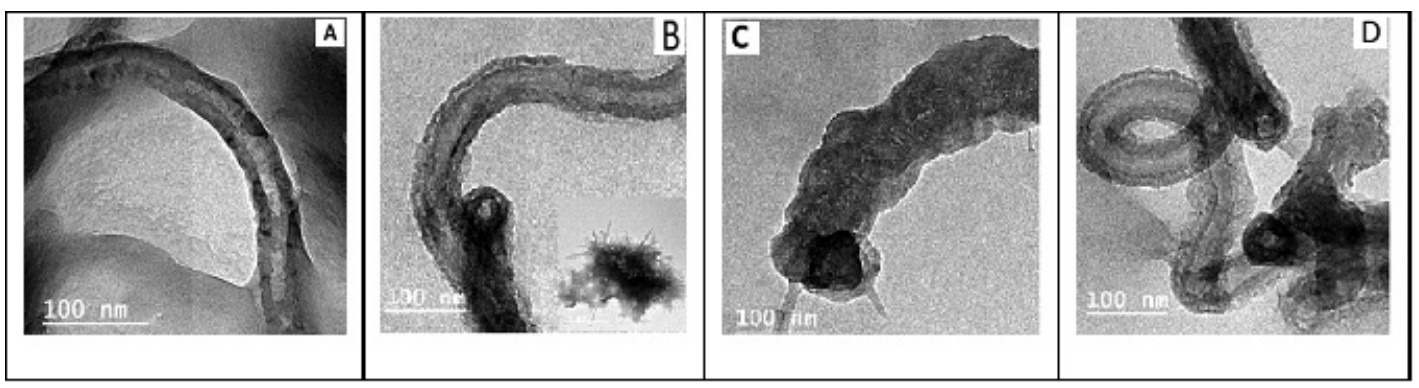

Figure 1. TEM of (A) MWCNT/chitosan nanocomposite, (B) nanocomposite loaded with curcumin, (C) loaded with curcumin derivative, and (D) loaded with 5-Fluorouracil. 
composite was constructed by solution processing method by mixing a dispersion of modified MWCNT in chitosan solution.

Then, loading of drugs was achieved by incorporating required volume of the drug solution into solution of chitosan or Cs/MWCNTs composite by sonication for 10 minutes and stirred for 16 hours at room temperature (Zhang et al., 2009).

\section{Morphology analysis}

The morphological studies were performed using the TEM for Cs/MWCNTs nanocomposite before and after loading of the drugs and represented in Figure 1. The TEM images showed that the surface topography of MWCNTs changed significantly proving uniform dispersion of CNT in chitosan which proves that surface of MWCNTs is covered with biopolymer chitosan, simultaneous with the wrapping of the polymers to the surface of MWCNTs (Fig. 1(A)). This might be attributed to the pi bond interaction of CNT with chitosan amino and hydroxyl groups (Venkatesan et al., 2014).

After loading of drugs, TEM images were depicted in Figure 2(B-D) where the microscopic analysis for samples after the loading of each drug allowed to observe the morphological changes. The samples were compared to the morphology of neat composite.
The presence of significant additional structure on the surface of nanotubes after each drug loading could be detected that may refer to the loading of the high amount of drugs and well contamination and functionalization of the MWCNTs with the chitosan.

\section{Entrapment Efficiency}

Drug entrapment efficiency (EE) for the three studied anticancer drugs in the chitosan and MWCNT/chitosan nanocomposite was measured using the indirect method. Precipitation of the polymer nanocomposite was attempted by dropping a few drops of $\mathrm{NaOH}$ solution in the acetic chitosan solution loaded by the drug, then separated by centrifugation at $3,000 \mathrm{rpm}$ and the free drug was measured in the filtrate using UV-spectrophotometer.

Drug EE values for both chitosan and Cs/MWCNTs nanocomposite were represented in Table 1 and it was noted that $\mathrm{EE}$ values of Cs/MWCNTs are quite different from that of chitosan. It was noticed that the presence of CNT with chitosan in the nanocomposite caused raising of the amount of drug loaded, where, for curcumin EE increased from $25 \%$ to $72 \%$ and for its derivative EE increased from $33 \%$ to $80 \%$. While EE for 5-fluorouracil increased from $27 \%$ to $70 \%$. Referring that drug-loading efficiency

Table 1. Drug entrapment efficiency EE for Cs and Cs-MWCNT nanocomposite.

\begin{tabular}{ccccccc}
\hline & \multicolumn{2}{c}{ Chitosan } & \multicolumn{2}{c}{ Chitosan/MWCNT nanocomposite } \\
\cline { 2 - 6 } & Curcumin & $\begin{array}{l}\text { Curcumin } \\
\text { derivative }\end{array}$ & 5-Fluorouracil & Curcumin & $\begin{array}{l}\text { Curcumin } \\
\text { derivative }\end{array}$ & 5-Fluorouracil \\
\hline EE\% (\%) & 25 & 33 & 27 & 72 & 80 & 70 \\
\hline
\end{tabular}

Where, EE\%: entrapment efficiency percentage

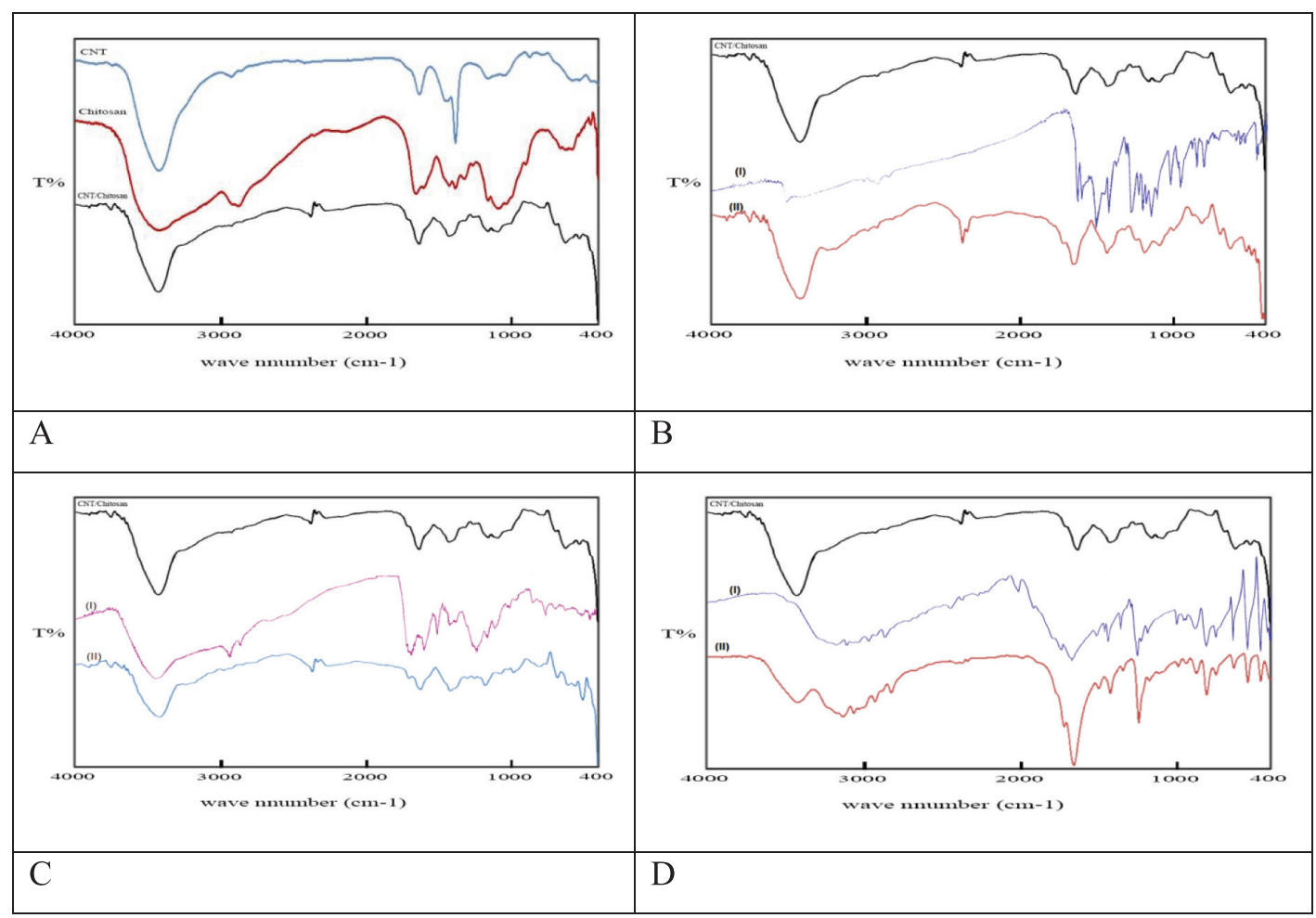

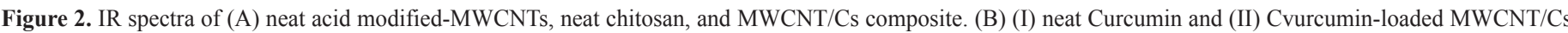

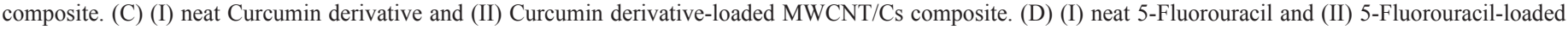
MWCNT/Cs composite. 
of Cs/MWCNTs is much higher than that of chitosan. It can be inferred from that cross-linked chitosan cannot interact effectively with drugs. Drugs may interact with Cs/MWCNTs by intermolecular interactions or loaded in the inner cavities of CNTs in addition to the polymer matrix (Luo et al., 2011; Peng et al., 2013).

\section{FTIR analysis}

FTIR spectra of acid-treated MWCNTs, Cs, and Cs/ MWCNTs are shown in Figure 2(A). In CNT spectra, the intense and wide band at $3,220 \mathrm{~cm}^{-1}$ is attributed to the vibration of $-\mathrm{OH}$ in carboxyl group, the characteristic peaks at $1,513 \mathrm{~cm}^{-1}$ and $1,040 \mathrm{~cm}^{-1}$ are due to the vibration of $\mathrm{C}=\mathrm{O}$ and $\mathrm{C}-\mathrm{O}$, respectively. In $\mathrm{Cs} /$ MWCNT spectra, the intense bands at $3,480 \mathrm{~cm}^{-1}$ and $1,040 \mathrm{~cm}^{-1}$ are attributed to the stretching vibration of $\mathrm{N}-\mathrm{H}$ and $\mathrm{C}=\mathrm{O}$ in - $\mathrm{CONH}$, respectively, which confirm that the polymer was grafted onto MWCNTs via the amide linkage (Peng et al., 2013).

IR spectra for the Cs/MWCNT composite after loading the drugs were presented in Figure 2(B-D) for curcumin, curcumin derivative, and 5-fluorouracil, respectively. Where the spectra for drug-loaded Cs/MWCNT composite were compared with that of the free drug and that of the neat Cs/MWCNT composite. It is noted that the main characteristic peaks for functional groups in both of free drug and the neat composite appeared in the spectra after loading. This fact confirms that there is no chemical interaction between the drug and the composite maintaining the active groups of the drugs (Moustafa et al., 2013).

\section{X-Ray Diffraction}

The XRD patterns of neat chitosan, neat MWCNTs, and Cs/MWCNTs composite are presented in Figure 3(A). It can be observed that neat chitosan exhibits one broad diffraction peak with $2 \theta$ values of $20.0^{\circ}$ that indicates the amorphous state of chitosan. For Cs/MWCNTs pattern, the dominant peak at
$2 \theta=26.2^{\circ}$ which is a characteristic of raw-CNTs still intense and sharp, indicating the good crystallinity of Cs/MWCNTs composite. So, the framework of nanotube still shows a strong influence on the properties of Cs/MWCNTs composite and also, grafting of chitosan on CNTs affects the intensity and peak position of the CNTs phase. It was proposed from these phenomena that they were related to a phase change in the structure of CNTs, in which chitosan had connected to the CNTs (Yang et al., 2015).

XRD patterns for the composites after loading of each curcumin, its derivative, and 5-fluorouracil were shown in Figure 3(B). It was observed that after loading of drugs in Cs/CNTs composite, many new varietal and low-intensity peaks appeared referring to the crystallinity of the Cs/CNTs phase is lower due to grafted chitosan. The absence of such sharp crystalline peaks confirmed the formation of an amorphous complex or disordered crystalline phase of the drug in the polymeric nanocomposites (Shaikh et al., 2009).

\section{Thermal Gravimetric Analysis (TGA)}

Thermal gravimetric analysis (TGA) is a simple and accurate method for studying the decomposition pattern and the thermal stability of chitosan, chitosan/CNT, and chitosan/ CNT loaded with different drugs that were studied within the temperature range of $50^{\circ} \mathrm{C}-700^{\circ} \mathrm{C}$ and the weight loss measurement was carried out at a heat flow rate of $10^{\circ} \mathrm{C} /$ minute under nitrogen (Kumar et al., 2014).

The results of TGA (Fig. 4) showed generally that the existence of MWCNTs resulted in increasing the thermal stability of the Cs/MWCNTs nanocomposite (curve-D) and even after loading the drugs, for curcumin, its derivative, and 5-Fluorouracil, with respect to the free chitosan.The TGA results which compare the temperatures at which the sample loses a certain percentage from its original weight are listed in Table 2 , where $T_{10}$ is the

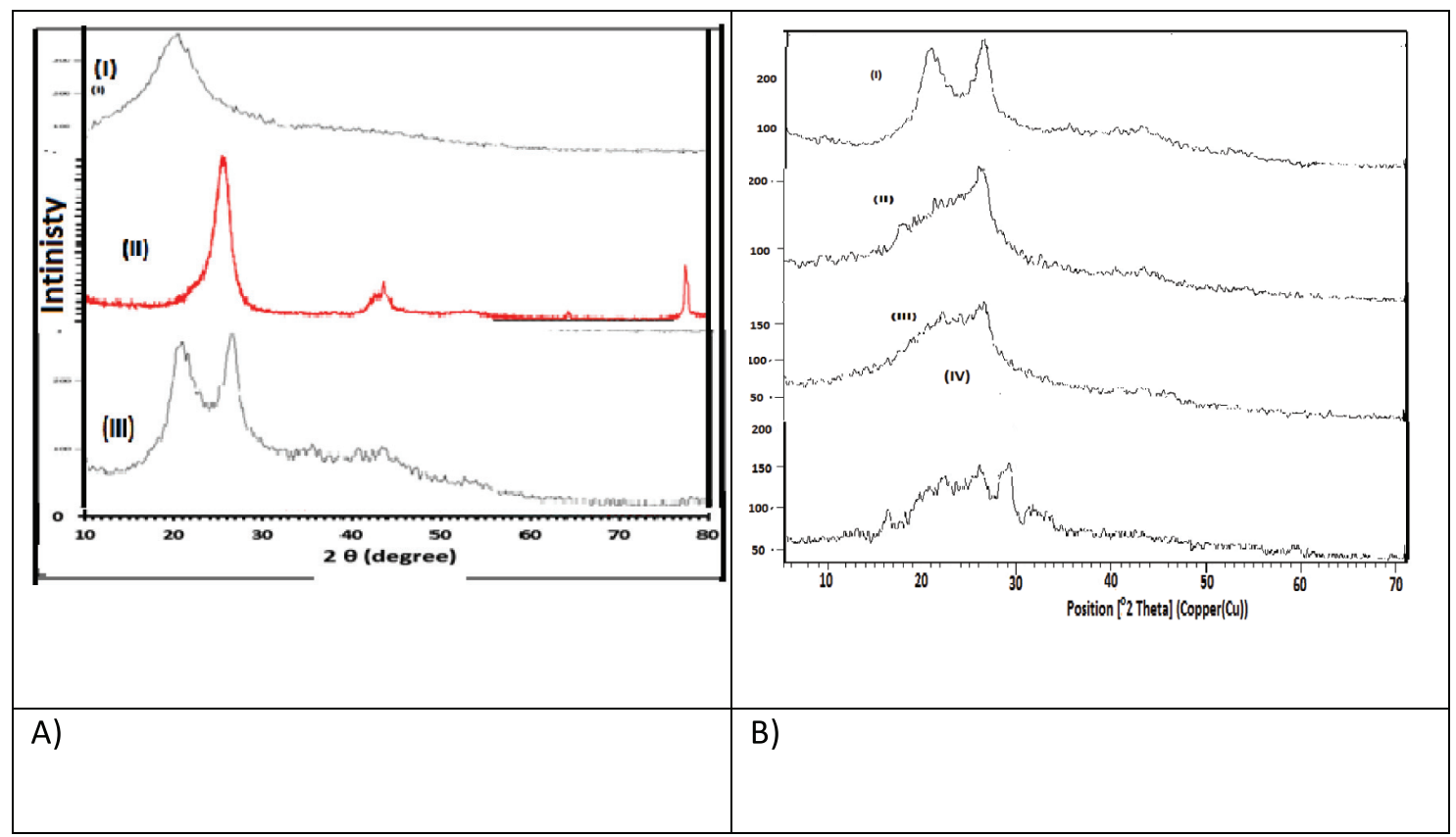

Figure 3. XRD for (A) (I) chitosan, (II) MWCNs, and (III) Cs/MWCNTs. (B) (I) Cs/MWCNT nanocomposite, (II) Curcumin loaded-Cs/MWCNT nanocomposite, (III) Curcumin derivative loaded-Cs/MWCNT nanocomposite, and (IV) 5-Fluorouracil loaded-Cs/MWCNT nanocomposite. 


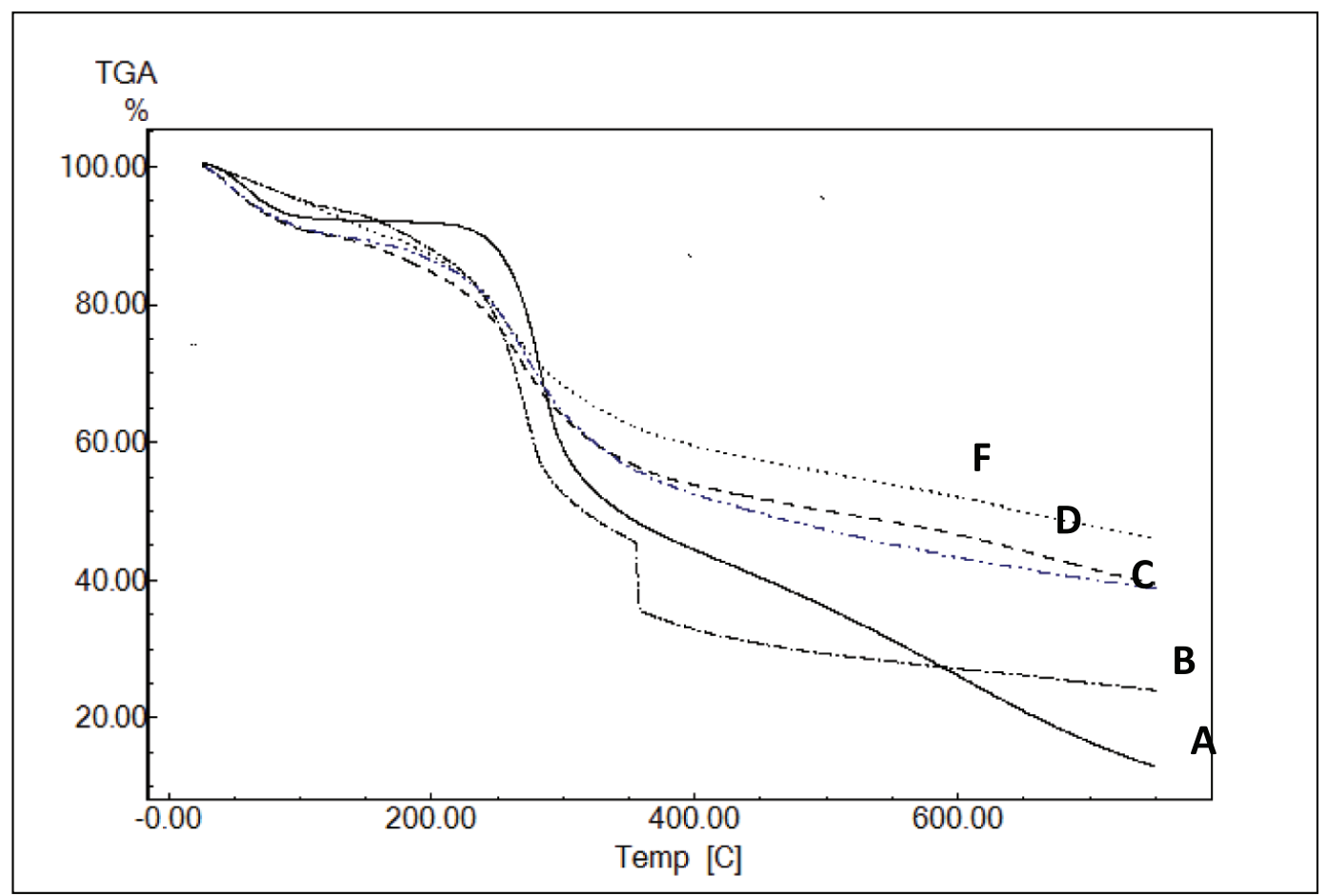

Figure 4. TGA thermograves of (A) Chitosan, (B) Chitosan/CNT/5-Fluorouracil, (C) Chitosan/CNT/Curcumin derivative, (D) Chitosan/CNT, and (F) Chitosan/CNT/ Curcumin.

temperature at which the sample loses $10 \%$ from its original weight, $\mathrm{T}_{30}$ is the temperature at which the sample loses $30 \%$ from its original weight and so on. The results show that pure chitosan is the least thermally stable sample, where the thermal stability increased by MWCNT addition (Abdel Salam et al., 2011).

The loading of the drug led to decrease in the thermal stability of the prepared chitosan/CNT, where the 5-Fluorouracil drug (B) causes the most decreasing in the thermal stability and curcumin derivative loading causes slightly decreasing the thermal stability decreasing for the prepared chitosan/CNT. While loading curcumin causing slightly increasing the thermal stability.

\section{Cytotoxicity}

The cytotoxicity experiments aimed to assess and compare the cytotoxicity of the curcumin-loaded Cs/MWCNT nanocomposite on breast cancer cells MCF-7 cells and normal retina cell line (RPE1 cells). Cytotoxicity measurements were performed using the MTT assay. The cell viability was measured for 48 hours after the addition of different concentrations of curcumin, curcumin loaded chitosan, or curcumin loaded Cs/MWCNT

Table 2. Degradation temperatures and weight loss of (A) Chitosan, (B) Chitosan/CNT/Fluorouracil, (C) Chitosan/CNT/Curcumin deivative, (D) Chitosan/CNT, and (F) Chitosan/CNT/Curcumin.

\begin{tabular}{cccccc}
\hline Degradation Temperature & A & B & C & D & F \\
\hline $\mathrm{T}_{10 \%}$ & 242.5 & 165.5 & 147 & 185 & 185 \\
$\mathrm{~T}_{30 \%}$ & 283.5 & 264 & 272 & 277 & 280 \\
$\mathrm{~T}_{\mathbf{5 0 \%}}$ & 342.5 & 316 & 432 & 493 & 631 \\
$\mathrm{~T}_{70 \%}$ & 550 & 472 & - & - & - \\
$\mathrm{T}_{90 \%}$ & 695 & - & - & - & - \\
\hline
\end{tabular}

nanocomposite ranging from 0.78 to $100 \mu \mathrm{g} / \mathrm{ml}$. The cell viability for chitosan was studied previously (Baharifar et al., 2016) and it was found to be around $69 \%$ depending on the concentration, $\mathrm{M}$. wt., and deacetylation degree of chitosan.

The results of cell viability measurement for curcumin encapsulated $\mathrm{Cs}$ or $\mathrm{Cs} / \mathrm{MWCNT}$ nanocomposite presented in Figure 5 showed a decrease in the mean viability percentages of the treated cells with respect to the control cells (Pandey et al., 2018). Also, it showed a decrease in the percentage of cell viability MCF-7 cancer cells compared with RPE1 normal cells, indicating to higher cytotoxicity on cancer MCF-7 cells compared with normal RPE1 cells. These results imply the effectiveness of encapsulation of curcumin with either of $\mathrm{Cs}$ or $\mathrm{Cs} / \mathrm{MWCNT}$ nanocomposite towards the specific destruction of the carcinogenic MCF-7 cells compared to RPE1 normal cells (Elbaz et al., 2016; Masloub et al., 2016). This means that Cur-loaded Cs and Cs/ MWCNT are not only cytotoxic but also selective. This may be attributed to the ability of CNTs to deliver drugs directly to the cells and tissues as they can penetrate the cellular membrane without causing apparent cell damage (Abdelbary et al., 2012).

\section{In-vitro drug release}

Studies of the release behavior of the applied anticancer drugs to the desired site is greatly important to formulate a successful cancer-targeted drug delivery system. So, the release behaviors of the drugs curcumin, its derivative, and 5-fluorouracil were studied in buffer solutions with two different $\mathrm{pH}$ values. In these studies, the release behavior from chitosan and the Cs/ MWCNTs were compared in the buffer solution with $\mathrm{pH} 7.4$ which represents $\mathrm{pH}$ of the blood and buffer solution with $\mathrm{pH} 1.2$ which represents the acidic media of the cancer cells or gastric fluid. 


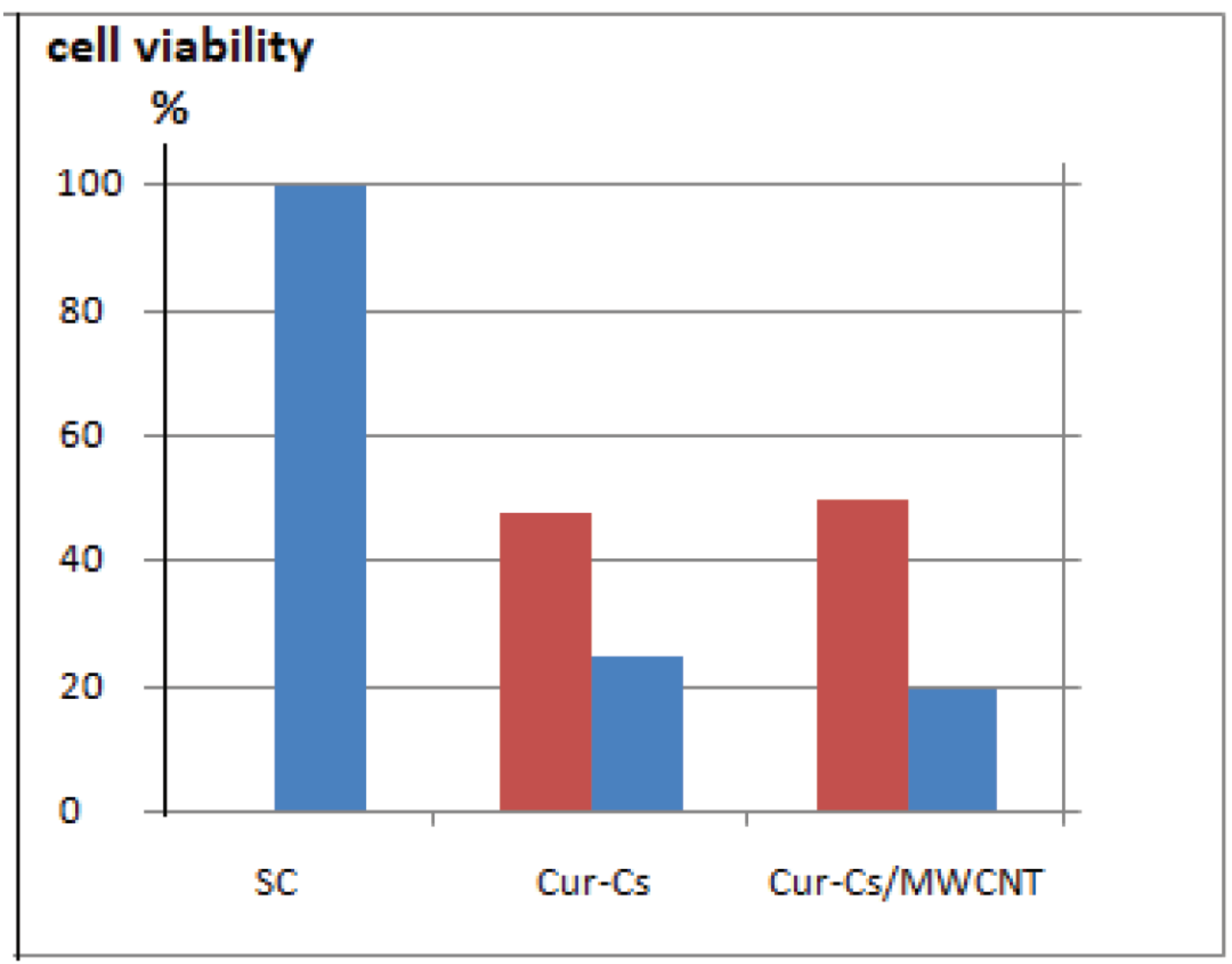

Figure 5. Plot of cell viability percentages for MCF-7 cells ( $\square$ ) and RPE1 cells ( $\square$ ) treated with curcumin encapsulated Cs or Cs/MWCNT nanocomposite with conc $100 \mu \mathrm{g} / \mathrm{ml}$ in cytotoxicity assay.

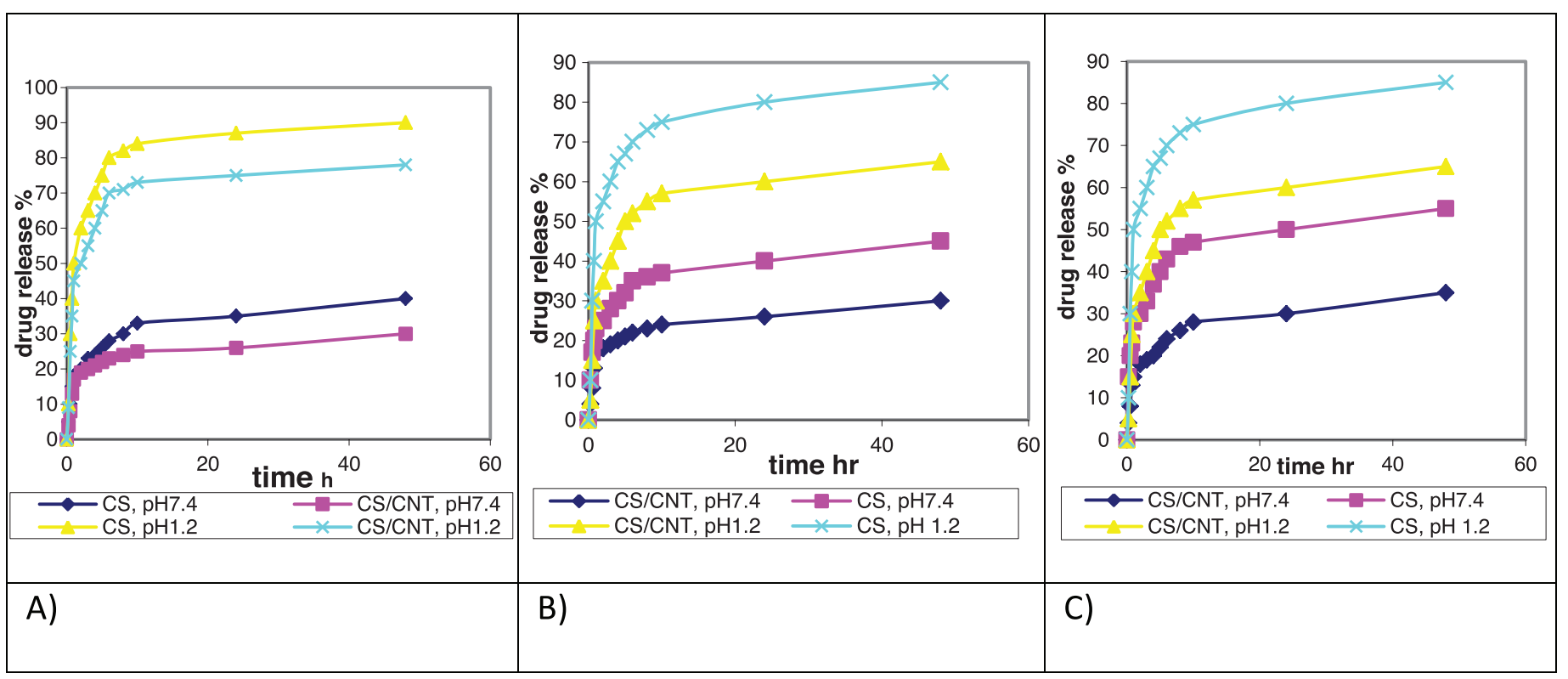

Figure 6. Cumulative release profile of drug from Cs/MWCNTs nanocomposite compared with the neat Cs in both pH 1.2 and $\mathrm{pH} 7.4$ fluid, (A) Curcumin, (B) curcumin derivative, and $(\mathrm{C}) 5$-fluorouracil. Where $(\longrightarrow) \mathrm{Cs}$ at $\mathrm{pH} 7.4,(-\longrightarrow) \mathrm{Cs} / \mathrm{MWCNTs}$ nanocomposite at $\mathrm{pH} 7.4,(-4), \mathrm{Cs} \mathrm{pH} 1.2(-x)$, and $\mathrm{Cs} /$ MWCNTs nanocomposite at $\mathrm{pH} 1.2$ 
Generally, Figure 6 represented the release of the drugs from the hydrogel that indicated an initial burst effect in first 30 minutes and then a gradual release of the drug began for all the investigated drug carriers either Cs or Cs/MWCNTs at different $\mathrm{pH}$ values. The initial burst drug release may be attributed to drug adsorbed on the surface in addition to the concentration gradient of the drugs between the gel and the media due to rapid swelling of the polymer.

Afterward, it is noted that the release rate of the drugs is $\mathrm{pH}$ dependent and strongly related to the swelling of both $\mathrm{Cs}$ and Cs/MWCNT in the two different fluids. Where $\mathrm{pH}$ value of the solution media has a great effect on the swelling degree and influence the molecular characteristics.

The release performance in the simulative gastric fluid $\mathrm{pH} 1.2$ was more obvious, where, in the acidic solution, repulsive forces between the drug molecules and CNTs collaborating with swelling effect force drug release to the solution.

A significant finding was that cumulative release from the Cs/MWCNTs nanocomposite particle carrier was slower than pure chitosan, at the two investigated $\mathrm{pH}$ values $(\mathrm{pH} 1.2$ and 7.4), that may be attributed to the drug encapsulated inside the interior cavities of MWCNTs (Peng et al., 2013), The profile of slow drug release indicates to a strong association between the drug and CNTs, that improve or even trigger the drug release successfully, that would be extremely fruitful for controlled drug release purposes (Wong et al., 2013). At the high $\mathrm{pH}$ of 7.4, chitosan is insoluble while in the acidic media the internal interaction between the drug and the carrier weakened and chitosan will be soluble. So, drug release from pure chitosan was very rapid at $\mathrm{pH}$ of 1.2. In contrast, drug release was far less rapid for the Cs/ MWCNTs nanocomposite, where the release from these matrices was significantly slower and controlled.

The in vitro drug release studies suggested that the carrier Cs or chitosan/CNT nanocomposite is $\mathrm{pH}$ sensitive that could benefit as cancer-targeted drug delivery where the acidic media of the cancer cells facilitates active drug release from NCs and increases drug bioavailability to cancer cells and leads to high therapeutic efficacy compared with normal cells (Elbaz et al., 2016). In chitosan/CNT nanocomposite, particles of the drug contributed strongly inside the nanotube's cavity which causing very slow drug release (Zhang et al., 2009).

\section{CONCLUSION}

The nanocomposite of $\mathrm{Cs} / \mathrm{MWCNTs}$ is a brilliant technique to improve the drug delivery efficiency resulting in long-term controlled sustained drug release and sensitive to $\mathrm{pH}$ of the dissolution media. The composite prepared delivers the drug without chemical interaction between the drug and the composite maintaining active groups of the drug as confirmed by FTIR and XRD. The presence of MWCNT in the polymeric nanocomposite permitted loading of high drug content and increased the thermal stability of the composite. The results of cytotoxicity assay measurement showed that the curcumin encapsulated Cs or Cs/MWCNT nanocomposite presented higher toxicity towards MCF-7 cancer cells compared with RPE1 normal cells indicating to the selective effectiveness of curcumin nanocomposite towards the destruction of the carcinogenic MCF-7 cells.
In vitro drug release studies confirmed the increase in the prolongation of sustained and controlled release for the three drugs applied that is kindly indicating that there is a strong inherence of the drug inside CNT's cavity and polymer network, strategies to improve or even trigger the release of the drug successfully, would be extremely fruitful for controlled drug release purposes.

\section{ACKNOWLEDGMENTS}

The authors acknowledge the funding agencies National Research Center, Egypt (Project number 10140004).

\section{CONFLICT OF INTEREST}

All authors (HE Nasr and WS Mohamed) declare that they have no conflict of interest.

\section{REFERENCES}

Abdel Salam M, Makki MSI, Abdelaal MYA. Preparation and characterization of multi-walled carbon nanotubes/chitosan nanocomposite and its application for the removal of heavy metals from aqueous solution J Alloy Comp 2011; 509:2582-7.

Abdelbary EMA, Waqar A, Israr UH, Vinod DR, Antony DE. Carbon nanotubes in cancer therapy and drug delivery. J Drug Delivery 2012; 2012:1-10

Baharifar H, Amani A. Cytotoxicity of chitosan/streptokinase nanoparticles as a function of size: an artificial neural networks study. Nanomedicine 2016; 12:171-80.

Bassyouni FA, Abu-Baker SM, Mahmoud K, Moharam M, El-Nakkady SS, Abdel-Rehim M. Synthesis and biological evaluation of some new triazolo[1,5-a]quinoline derivatives as anticancer and antimicrobial agents. RSC Adv 2014; 46:24131-41.

Benito P, Herrero M, Labajos FM, Rives V, Royob C, Latorre $\mathrm{N}$, et al. Production of carbon nanotubes from methane use of $\mathrm{Co}-\mathrm{Zn}-\mathrm{Al}$ catalysts prepared by microwave-assisted synthesis. Chem Eng J 2009; 149:455-62.

Dang JM, Leong KW. Natural polymers for gene delivery and tissue engineering. Adv Drug Deliv Rev 2006; 58:487-99.

Debbage P. Targeted drugs and nanomedicine: present and future. Curr Pharm Des 2009; 15:153-72.

El-Sharkawy ER, Mahmoud K. Cytotoxity of two new coumarin derivatives isolated from Launaea mucronata. Nat Prod Res 2016 30:394-8.

Elbaz NM, Ziko L, Siam R, Mamdouh W. Core-shell silver/ polymeric nanoparticles-based combinatorial therapy against breast cancer in-vitro. Sci Rep 2016; 6:30729. doi:10.1038/srep30729

Jia YX, Li HL, Wang M, Wu LY, Hu YD. Carbon nanotube: possible candidate for forward osmosis. Sep Purif Technol 2010; 75:55-60

Joshi GV, Kevadiya BD, Patel HA, Bajaj HC, Jasra RV. Montmorillonite as a drug delivery system: intercalation and in vitro release of timolol maleate. Int J Pharm 2009; 374:53-7.

Karimi EZ, Zebarjad SM, Khaki JV, Izadi H. Production of carbon nanotubes using mechanical milling in the presence of an exothermic reaction. J Alloy Comp 2010; 505:37-42.

Kumar SSD, Mahadevan S, Vijayaraghavan R, Mandal AB, MacFarlane DR. Curcumin loaded poly(2-hydroxyethyl methacrylate) nanoparticles from gelled ionic liquid-in vitro cytotoxicity and anticancer activity in SKOV-3 cells. Eur J Pharm Sci 2014a; 51:34-44.

Kumar SSD, Mahesh A, Mahadevan S, Mandal AB. Synthesis and characterization of curcumin loaded polymer/lipid based nanoparticles and evaluation of their antitumor effects on MCF-7 cells. Biochimica et Biophysica Acta 2014b; 1840:1913-22.

Laka M, Chernyavskaya S. Preparation of chitosan powder and investigation of its properties. Proc Estonian Acad Sci Chem 2006; $55: 78-84$ 
Liu L, Sun L, Wu Q, Guo W, Li L, Chen Y, et al. Curcumin loaded polymeric micelles inhibit breast tumor growth and spontaneous pulmonary metastasis. Int J Pharm 2013; 443:175-82.

Luo X, Matranga C, Tan S, Alba N, Cui XT. Carbon nanotube nanoreservior for controlled release of anti-inflammatory dexamethasone. Biomaterials 2011; 32:6316-23.

Masloub SM, Elmalahy MH, Sabry D, Mohamed WS, Ahmed SH. Comparative evaluation of PLGA nanoparticle delivery system for 5 -fluorouracil and curcumin on squamous cell carcinoma. Arch Oral Biol 2016; 64:1-10

Moghassemi S, Hadjizadeh A. Nano-niosomes as nanoscale drug delivery systems. J Control Release 2014; 185:22-36.

Mosmann T. Rapid colorimetric assay for cellular growth and survival: application to proliferation and cytotoxicity assays. J Immunol Methods 1983; 65:55-63.

Moustafa AB, Sobh RA, Rabie AM, Nasr HE, Ayoub MMH. Synthesis and in vitro release of guest drugs-loaded copolymer nanospheres MMA/HEMA via differential microemulsion polymerization. J App Polym Sci 2013; 129:853-65.

Naficy S, Razal JM, Spinks GM, Wallace GG. Modulated release of dexamethasone from chitosan-carbon nanotube films. Sens Actuators A $2009 ; 155: 120-4$.

Nivethaa EAK, Dhanavel S, Rebekah A, Narayanan V, Stephen A. A comparative study of 5-Fluorouracil release from chitosan/silver and chitosan/silver/MWCNT nanocomposites and their cytotoxicity towards MCF-7. Mater Sci Eng C 2016; 66:244-50.

Pandey P, Sayyed U, Tiwari R, Pathak N, Siddiqui MH, Bajpai P. Anticancer and apoptosis inducing effects of curcumin against gall bladder carcinoma. Int J Res Pharm Sci 2018; 9:68-77.

Paul W, Sharma CP. Chitosan, a drug carrier for the 21 st century: a review. S.T.P. Pharma Sci 2000; 10:5-22.

Peng X, Zhuangc Q, Pengb D, Dongc Q, Tanc L, Jiaoc F, et al. Sustained release of naproxen in a new kind delivery system of carbon nanotubes hydrogel. Iran J Pharm Res 2013; 12: 581-6.

Prakash S, Malhotra M, Shao W, Tomaro-Duchesneau C, Abbasi S. Polymeric nanohybrids and functionalized carbon nanotubes as drug delivery carriers for cancer therapy. Adv Drug Deliv Rev 2011; 63:1340-51.

Prato M, Kostarelos KAB. Functionalized carbon nanotubes in drug design and discovery. Acc Chem Res 2008; 41:16-7.

Rezq AM, Abdel Aziz MT, Al-Malki AL. Gelatin, a novel curcumin drug carrier system. WO/2011/100984. World Intellect Prop Org (WIPO); 2011. http://patentscope.Wipoint/search/en/detail. jsf\%3 Bjsessionid+90C05C 7570-FE02B89EBE9013FC25D794. wapp1?docId=WO2011100984\&recNum $=$ Desc $\& \operatorname{maxRec}=8021524$

Sahoo NG, Rana S, Cho JW, Li L, Chan SH. Polymer nanocomposites based on functionalized carbon nanotubes. Prog Polym Sci $2010 ; 35: 837-67$.

Sangsanoh P, Supaphol P. Stability improvement of electrospun chitosan nanofibrous membranes in neutral or weak basic aqueous solutions. Biomacromolecules 2006; 7:2710-4.

Scheibe B, Borowiak-Palen E, Kalenczuk RJ. Enhancement of thermal stability of multiwalled carbon nanotubes via different silanization routes. J Alloy Compd 2010; 500: 117-24.

Shaikh J, Anko la DD, Beniwal V, Singh D, Kumar MNVR. Nanoparticle encapsulation improves oral bioavailability of curcumin by at least 9-fold when compared to curcumin administered with piperine as absorption enhancer. Eur J Pharm Sci 2009; 37:223-30.

Sobh RA, Mohamed WS, Moustafa AB, Nasr HE. Encapsulation of curcumin and curcumin derivative in polymeric nanospheres. Polym Plast Technol Eng 2015; 54:1457-67.

Sobh RA, Nasr HE, Moustafa AB, Mohamed WS. Tailoring of anticancer drugs loaded in MWCNT/Poly(MMA-co-HEMA) nanosphere composite by using in situ microemulsion polymerization. J Pharm Invest 2018. https://doi.org/10.1007/s40005-018-0390-8

Valot P, Baba M, Nedelec J-M, Sintes-Zydowicz N. Effects of process parameters on the properties of biocompatible Ibuprofen-loaded microcapsules. Int J Pharm 2009; 369:53-63.

Venkatesan J, Jayakumar R, Mohandas A, Bhatnagar I, Kim S-K. Antimicrobial activity of chitosan-carbon nanotube hydrogels. Materials 2014; 7:3946-55

Wang JJ, Zeng ZW, Xiao RZ, Xie T, Zhou GL, Zhan XR, et al. Recent advances of chitosan nanoparticles as drug carriers. Int J Nanomed $2011 ; 6: 765-74$.

Wong BS, Yoong SL, Jagusiak A, Panczyk T, Ho HK, Ang WH, et al. Carbon nanotubes for delivery of small molecule drugs. Adv Drug Deliv Rev 2013; 65:1964-2015.

Xiao X, Wang Y. Emulsion copolymerization of fluorinated acrylate in the presence of a polymerizable emulsifier. Colloids Surf A 2009; 348:151-6.

Yang HC, Hon MH. The effect of the molecular weight of chitosan nanoparticles and its application on drug delivery. Microchem J 2009; 92:87-91.

Yang S, Shao D, Wang X, Hou G, Nagatsu M, Tan X, et al. Design of chitosan-grafted carbon nanotubes: evaluation of how the $-\mathrm{OH}$ functional group affects $\mathrm{Cs}^{+}$adsorption. Mar Drugs 2015; 13:3116-31.

Yu JG, Huang KL, Yang QQ, Liu SQ, Tang JC. Research progress of carbon nanotubes as drug carriers. Acta Pharm Sinica 2008; 43:985-91.

Zhang X, Meng L, Lu Q, Fei Z, Dyson PJ. Targeted delivery and controlled release of doxorubicin to cancer cells using modified single wall carbon nanotubes. Biomaterials 2009; 30:6041-7.

How to cite this article:

Sobh RA, Nasr HE, Mohamed WS. Formulation and in vitro characterization of anticancer drugs encapsulated chitosan/ multi-walled carbon nanotube nanocomposites. J App Pharm Sci 2019; 9(08):032-040. 